Research Article

\title{
Interim Storage of the Dalat Nuclear Research Reactor: Radiation Safety Analysis
}

\author{
Kien-Cuong Nguyen, ${ }^{1}$ Vinh-Vinh Le, ${ }^{1}$ Ton-Nghiem Huynh, ${ }^{1}$ Ba-Vien Luong, \\ Nhi-Dien Nguyen $\mathbb{1}^{1},{ }^{1}$ and Hoai-Nam Tran $\circledast^{2,3}$ \\ ${ }^{1}$ Dalat Nuclear Research Institute, VINATOM, 01 Nguyen Tu Luc, Dalat 66000, Lamdong, Vietnam \\ ${ }^{2}$ Institute of Fundamental and Applied Sciences, Duy Tan University, Ho Chi Minh City 700000, Vietnam \\ ${ }^{3}$ Faculty of Natural Sciences, Duy Tan University, Da Nang 550000, Vietnam
}

Correspondence should be addressed to Nhi-Dien Nguyen; diennn.re@dnri.vn and Hoai-Nam Tran; tranhoainam4@dtu.edu.vn

Received 4 September 2019; Accepted 26 November 2020; Published 8 December 2020

Academic Editor: Massimo Zucchetti

Copyright (c) 2020 Kien-Cuong Nguyen et al. This is an open access article distributed under the Creative Commons Attribution License, which permits unrestricted use, distribution, and reproduction in any medium, provided the original work is properly cited.

\begin{abstract}
Radiation safety analysis of a new interim storage of the Dalat Nuclear Research Reactor (DNRR) for keeping spent high enriched uranium (HEU) fuel bundles during the core conversion to low enriched uranium (LEU) fuel had been performed and presented. The photon source and decay heat of the spent HEU fuel bundles were calculated using the ORIGEN2.1 code. Gamma dose rates of the spent fuel interim storage were evaluated using the MCNP5 code with various scenarios of water levels in the reactor tank and cooling time. The radiation safety analysis shows that the retention of 106 spent HEU fuel bundles at the interim storage together with a core of $92 \mathrm{LEU}$ fuel bundles meets the requirements of radiation safety. The results indicate that in the most severe case, i.e., the complete loss of water in the reactor tank, the operators still can access the reactor hall to mitigate the accident within a limited time. Particularly, in the control room, the dose rate of about $1.4 \mu \mathrm{Sv} / \mathrm{h}$ is small enough for people to work normally.
\end{abstract}

\section{Introduction}

The Dalat Nuclear Research Reactor (DNRR) is a $500 \mathrm{~kW}$ pool-type research reactor, which is operated by the Dalat Nuclear Research Institute, VINATOM, located in Dalat, Vietnam. In the early 1980 s, the DNRR was reconstructed and upgraded from the $250 \mathrm{~kW}$ TRIGA Mark-II reactor, which was built in the early 1960s and operated on Russian VVR-M2 fuel type $[1,2]$. The reactor core consists of 121 hexagonal cells including fuel bundles, control rods, irradiation channels, and beryllium blocks. The active core has a diameter of about $46.48 \mathrm{~cm}$ and a height of $60 \mathrm{~cm}$. The active core is surrounded by a graphite reflector with the thickness of $30.5 \mathrm{~cm}$. The first core was loaded with 88 high enriched uranium (HEU) fuel bundles with ${ }^{235} \mathrm{U}$ enrichment of $36 \mathrm{wt} \%$. The first criticality of the DNRR was achieved on November 1st, 1983, and the full power operation was achieved in March 1984 [2]. Due to the international concerns on the use of HEU fuel, the core conversion to low enriched uranium (LEU) fuel was started in 2007. In the framework of the program on Russian Research Reactor Fuel Return (RRRFR) and the program on Reduced Enrichment for Research and Test Reactor (RERTR), the DNRR core was partly converted from HEU fuel to LEU fuel with ${ }^{235} \mathrm{U}$ enrichment of $19.75 \mathrm{wt} \%$ in September 2007. The full core conversion to LEU fuel was performed during the period from November 24th, 2011, to January 13th, $2012[2,3]$.

During and after the core conversion of the DNRR, one of the important tasks is the management of the spent fuel. Interim wet storage capacity is needed for cooling the spent HEU fuel bundles for a period of a few months to several years before transferring them to a spent fuel pool or returning them to Russian Federation. The existing storage capacity of the DNRR is capable to contain 72 fuel bundles. Thus, in addition to the available storage, a new rack was designed and installed for increasing the storage capacity of 106 spent HEU bundles during the restart-up 
of a new LEU fuel core. In the design of the new interim storage, radiation safety and criticality safety analysis has been conducted.

In this paper, we present the radiation safety analysis of the newly designed interim wet storage of the DNRR. The radiation safety was estimated based on the evaluation of the gamma dose rates induced by the spent HEU fuel bundles in the interim storage together with the new LEU core. The calculations were performed at various cooling times and water pool levels. For the most conservative case, the HEU fuel bundles were assumed to have the burnup of $30 \%$ loss of ${ }^{235} \mathrm{U}$. The burnup dependent cross sections of the VVR-M2 fuel type to be used in the ORIGEN2.1 code were generated using WIMS-ANL [4-6]. The ORIGEN2.1 code was then used to calculate the concentration and activities of the fission products and actinides, and the decay heat of the fuel bundle. The 18 energy-group photon flux at different cooling times obtained from ORIGEN2.1 was used to specify source distribution in the MCNP5 code to calculate the gamma dose rates at various positions in the reactor hall including the reactor top cover, shielding block, and the control room [7].

This paper is organized as follows. Section 2 describes briefly the calculation method of the gamma dose rate using ORIGEN2.1 and MCNP5. Section 3 presents the results and discussion on the radiation safety analysis. The gamma dose rates at different locations in the reactor hall have been evaluated. Finally, some concluding remarks are given in Section 4.

\section{The DNRR and Calculation Method}

2.1. Description of the DNRR. Table 1 and Figure 1 show the configuration and the detailed parameters of the HEU and LEU fuel bundles of the DNRR. The outer tube has a hexagonal sharp, and the two inner tubes are cylindrical. The two fuel bundles have a similar outer shape but with different thickness of fuel meat and cladding. The LEU fuel bundle has a lower ${ }^{235} \mathrm{U}$ enrichment (19.75 wt\%) but the thickness of $0.94 \mathrm{~cm}$ and the density of uranium fuel meat are greater than that of the HEU bundle, which lead to the higher total mass of ${ }^{235} \mathrm{U}$.

Figure 2 displays the vertical view of the DNRR reactor. The core consists of 121 hexagonal cells including fuel bundles, control rods, irradiation channels, and beryllium blocks. The reactor core is controlled by seven control rods: two safety rods (SR), four shim rods (ShR), and one automatic regulating rod (AR). The safety and shim rods are made of boron carbide $\left(\mathrm{B}_{4} \mathrm{C}\right)$, while the automatic regulating rod is made of stainless steel. The active core height is $60 \mathrm{~cm}$. The thickness of the graphite reflector is $30.5 \mathrm{~cm}$. The core and the graphite reflector are placed in the reactor pool. More detailed description of the DNRR reactor can be seen in $[8,9]$. Normally, the DNRR is operated continuously for a period of about 130 hours per month. The total operation time of the reactor is approximate 1300-1500 hours per year.

2.2. Calculation Method. Figure 3 describes the calculation diagram of the gamma dose rate using ORIGEN2.1 and MCNP5. In the radiation safety analysis, the ORIGEN2.1 code was used to calculate the activity and photon flux of the spent HEU and LEU fuel bundles during burnup and cooling time [5]. Since the library of ORIGEN2.1 does not contain the cross-section data of the VVR-M2 fuel type, the WIMS-ANL code was used for generating the burnup dependent cross sections of the VVR-M2 HEU and LEU fuel bundles to be used in ORIGEN2.1 [6]. A model of multiple concentric cylinders and SUPERCELL option of WIMSANL with 69 neutron energy groups based on the ENDF/BVI.8 data library were used to simulate the complex geometry and resonant materials of the VVR-M2 fuel bundles [10]. All factors related to the fuel geometry and the neutron spectrum have been treated in WIMS-ANL. Burnup calculations of the fuel lattice cells were performed from the beginning up to the burnup of $30 \%$ and $40 \%$ loss of ${ }^{235} \mathrm{U}$ for the HEU and LEU fuel, respectively. Then, the burnupdependent microscopic cross sections of heavy nuclides were collapsed from 69 energy groups to one energy group, which are later used in the ORIGEN2.1 code for calculating the activities, thermal decay, and gamma dose rates of the fuel bundles. In the calculations, the burnup processes of the fuel bundles were treated following the historical operation of the reactor. However, due to the complicated historical operation of the DNRR, only the historical operation of the latest 10 cycles was described accurately. The older cycles were divided into 50 days of operation and 285 days of cooling time alternatively as the sums of the operation and cooling time, respectively.

Burnup calculations of the HEU and LEU cores were conducted separately for obtaining the average axial burnup distributions of the HEU and LEU fuel bundles, respectively, using the REBUS-MCNP5 linkage code [11]. In the burnup and core physics calculations, the model describes the detailed reactor core including fuels, neutron trap, control rods, irradiation channels, graphite reactor, horizontal beam tubes, and water reflector. The dimensional parameters of the core model are $184.5 \mathrm{~cm}$ in height and $200 \mathrm{~cm}$ in diameter. The fuel bundle is divided into five axial nodes for obtaining the average axial burnup distribution, which is considerably adequate for determining the photon source distribution in the radiation safety analysis. Then, the burnup profile of the fuel bundle is determined, which is used as input to MCNP5 to specify the photon source in the axial direction together with photon fluxes.

The photon fluxes with 18 energy groups obtained in the ORIGEN2.1 calculations and the photon source distribution of a fuel bundle determined based on the burnup distribution in the REBUS-MCNP5 calculation were used as the input data in the MCNP5 model for calculating the gamma 
Table 1: Parameters of the HEU and LEU fuel bundles.

\begin{tabular}{lcc}
\hline Parameters & HEU & LEU \\
${ }^{235} \mathrm{U}$ enrichment $(\mathrm{wt} \%)$ & 36 & 19.75 \\
Total mass of ${ }^{235} \mathrm{U}$ in fuel bundle $(\mathrm{g})$ & 40.20 & 49.70 \\
Fuel meat composition & $\mathrm{U}-\mathrm{Al}$ Alloy & $\mathrm{UO}{ }_{2}+\mathrm{Al}$ \\
Uranium density of fuel meat $\left(\mathrm{g} / \mathrm{cm}^{3}\right)$ & 1.40 & 2.50 \\
Cladding material & $\mathrm{Al}$ alloy $(\mathrm{SAV}-1)$ & $\mathrm{Al}$ alloy $(\mathrm{SAV}-1)$ \\
Fuel element thickness $($ fuel meat and cladding) $(\mathrm{mm})$ & 2.50 & 2.50 \\
Fuel meat thickness $(\mathrm{mm})$ & 0.70 & 0.94 \\
Cladding thickness $(\mathrm{mm})$ & 0.90 & 0.78 \\
\hline
\end{tabular}

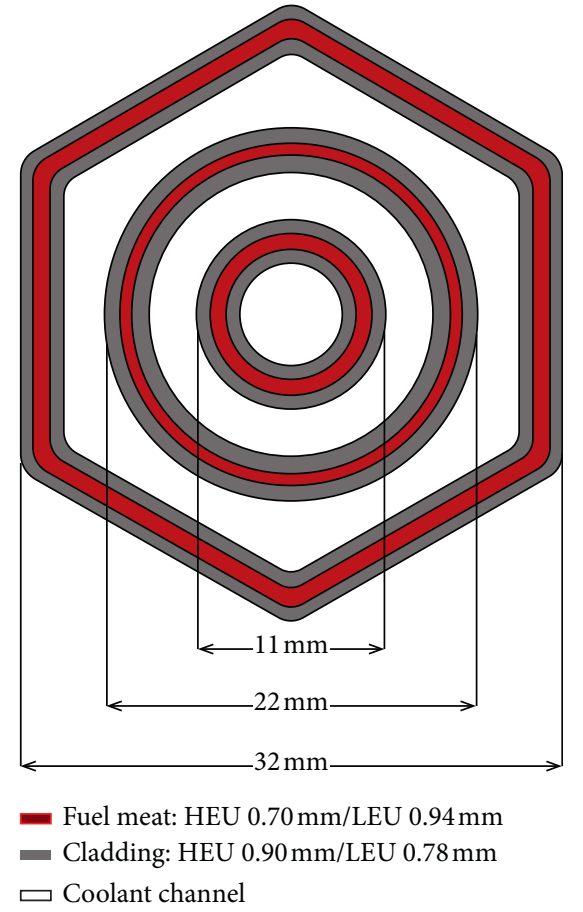

Figure 1: Cross-sectional view of the HEU and LEU fuel bundles of the DNRR.

dose rate [7]. In the shielding analysis using MCNP5, the LEU core, the interim storage of spent HEU fuel bundles, and surrounding components such as concrete walls, reactor hall, and control room were simulated. Figure 4 shows the MCNP5 model of the DNRR reactor with the surrounding components for calculating the gamma dose rates at various positions in the reactor hall such as the top of reactor tank, intermediate floors, and reactor hall and control room. The dimensional model is expanded to the reactor hall and the control room, i.e., $1517 \mathrm{~cm}$ in height and $2630 \mathrm{~cm}$ in diameter. Because of the complicated structure of the DNRR with concrete shielding, nonanalog MCNP5 calculations were performed for obtaining gamma dose rate. Weight window techniques depending on space and energy for variance reduction were applied for increasing the photon population in the regions with low material densities and far from the source. In the MCNP5 model, the concrete wall was radially divided into 25 meshes with an equal distance of $10 \mathrm{~cm}$. The water region in the reactor tank was radially divided into five equal volume regions. The flux to dose conversion factors taken from ANSI/ANL-6.1.1-1977 was used to convert the photon flux to gamma dose rate [12].

Figure 5 illustrates the arrangement of the spent fuel bundles in the interim storage. In order to simplify the calculation model, the concrete shielding blocks were described as cylinders instead of octagonal shapes in reality. Because the gamma dose rates at positions close to the reactor hall floor are mainly due to the scattered photons from the roof and indoor air, the contribution of photons passing through the shielding concrete is negligibly small (about $0.1 \%$ ). Thus, the modeled cylindrical shape of the concrete blocks would not affect significantly to the calculation results. In the radiation shielding analysis model using the MCNP5 code, two photon sources were considered: the interim storage of $106 \mathrm{HEU}$ bundles with the average burnup of $30 \%$ loss of ${ }^{235} \mathrm{U}$ and the core of 92 LEU bundles with the average burnup of $40 \%$ loss of ${ }^{235} \mathrm{U}$. In the MCNP5 calculations, the number of histories of $3 \times 10^{9}$ was chosen so that the statistical error of the gamma dose rate was within $1 \%$ at the locations of interest.

2.3. Calculation Scenarios. To perform radiation safety analysis of the DNRR with the new interim storage, it was assumed that the interim storage contained full capacity of 106 spent HEU fuel bundles and the core was loaded with $92 \mathrm{LEU}$ fuel bundles. All the spent HEU fuel bundles were assumed to have the same average burnup of $30 \%$ loss of ${ }^{235} \mathrm{U}$, and the LEU fuel bundles had the same average burnup of $40 \%$ loss of ${ }^{235} \mathrm{U}$. The burnup levels are equivalent to about $84150 \mathrm{MWd} / \mathrm{t}$ for $\mathrm{HEU}$ fuel and $61110 \mathrm{MWd} / \mathrm{t}$ for LEU fuel, respectively. The burnup of $30 \%$ loss of ${ }^{235} \mathrm{U}$ of HEU fuel was assumed for the most conservative case, since the average burnup of the 106 HEU bundles at the time of core conversion was determined of about $22 \%$ loss of ${ }^{235} \mathrm{U}$, whereas the burnup of $40 \%$ loss of ${ }^{235} \mathrm{U}$ of LEU fuel was assumed because the LEU bundle contains more ${ }^{235} \mathrm{U}$ amount than the HEU bundle, and after burnup, the remaining ${ }^{235} \mathrm{U}$ amount is approximate that in the spent HEU bundle. This means that two sources contributing to the gamma dose rates are considered: interim storage with 106 spent HEU fuel bundles and the LEU core. The radiation safety analysis was performed for various accidental scenarios of water levels in the reactor tank and at different cooling times. The water levels were assumed to decrease from $625 \mathrm{~cm}$ to $0 \mathrm{~cm}$ corresponding to the full water to the complete loss 


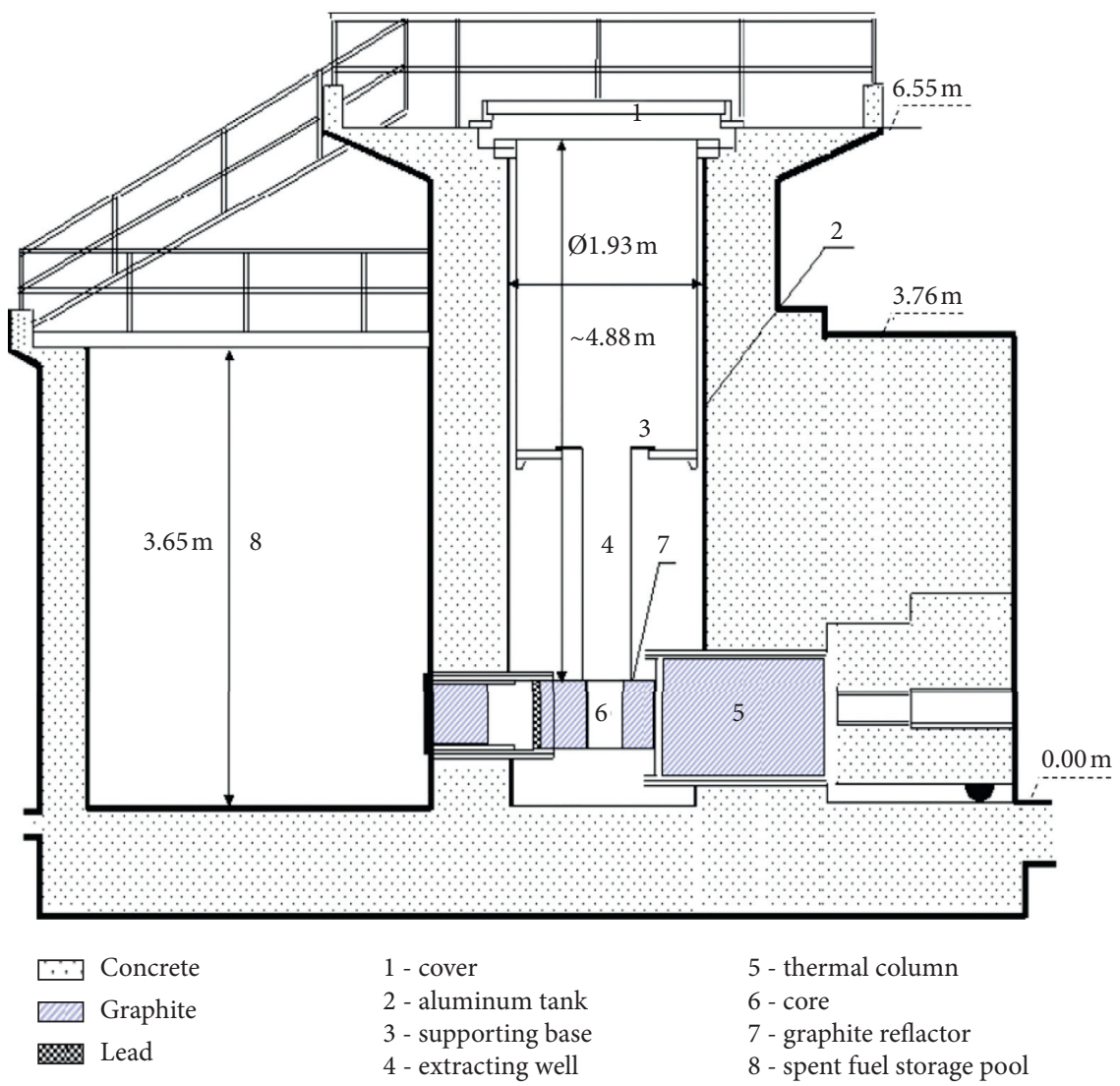

Figure 2: Vertical view of the DNRR.

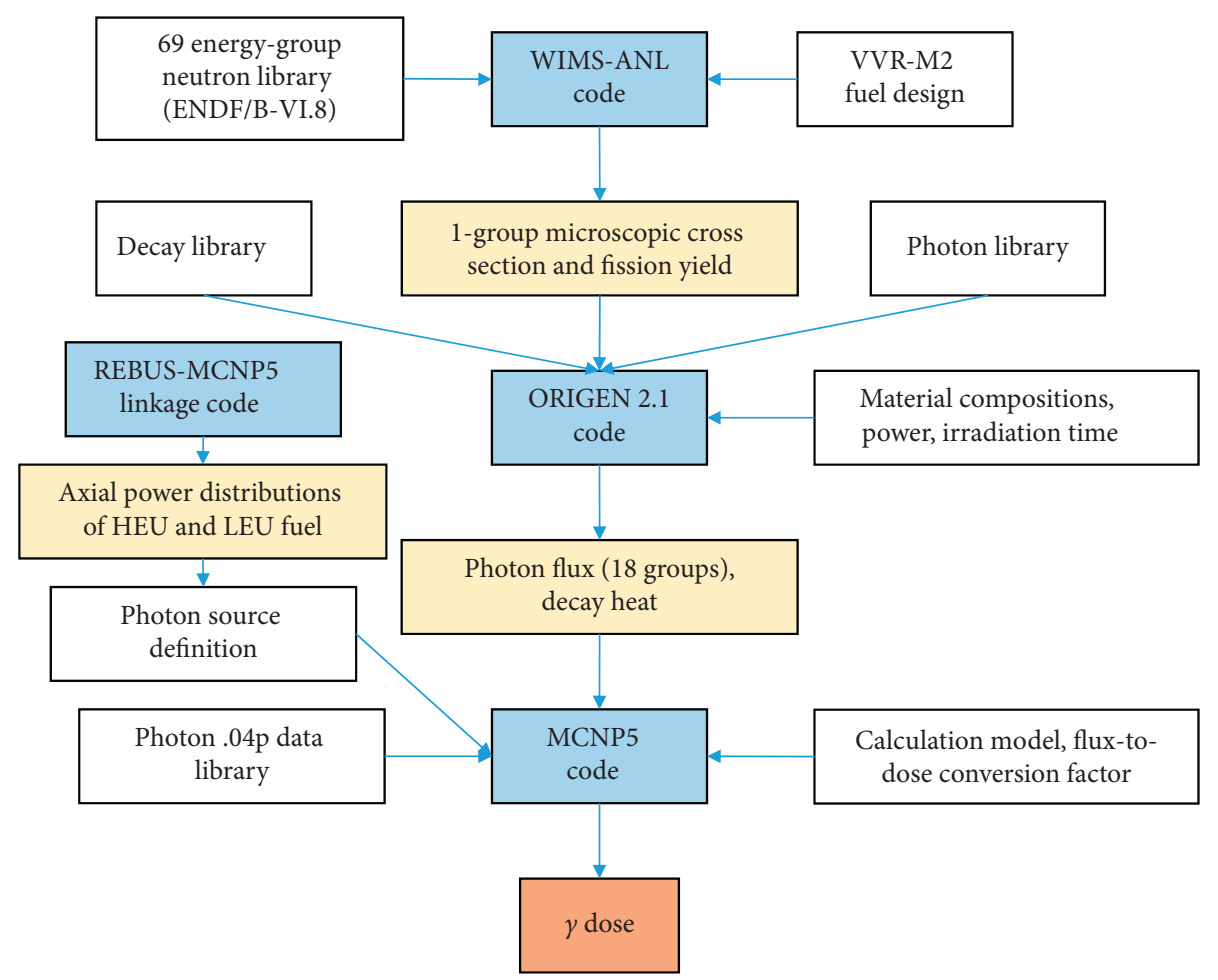

FIgURE 3: Diagram of the gamma dose rate calculation. 

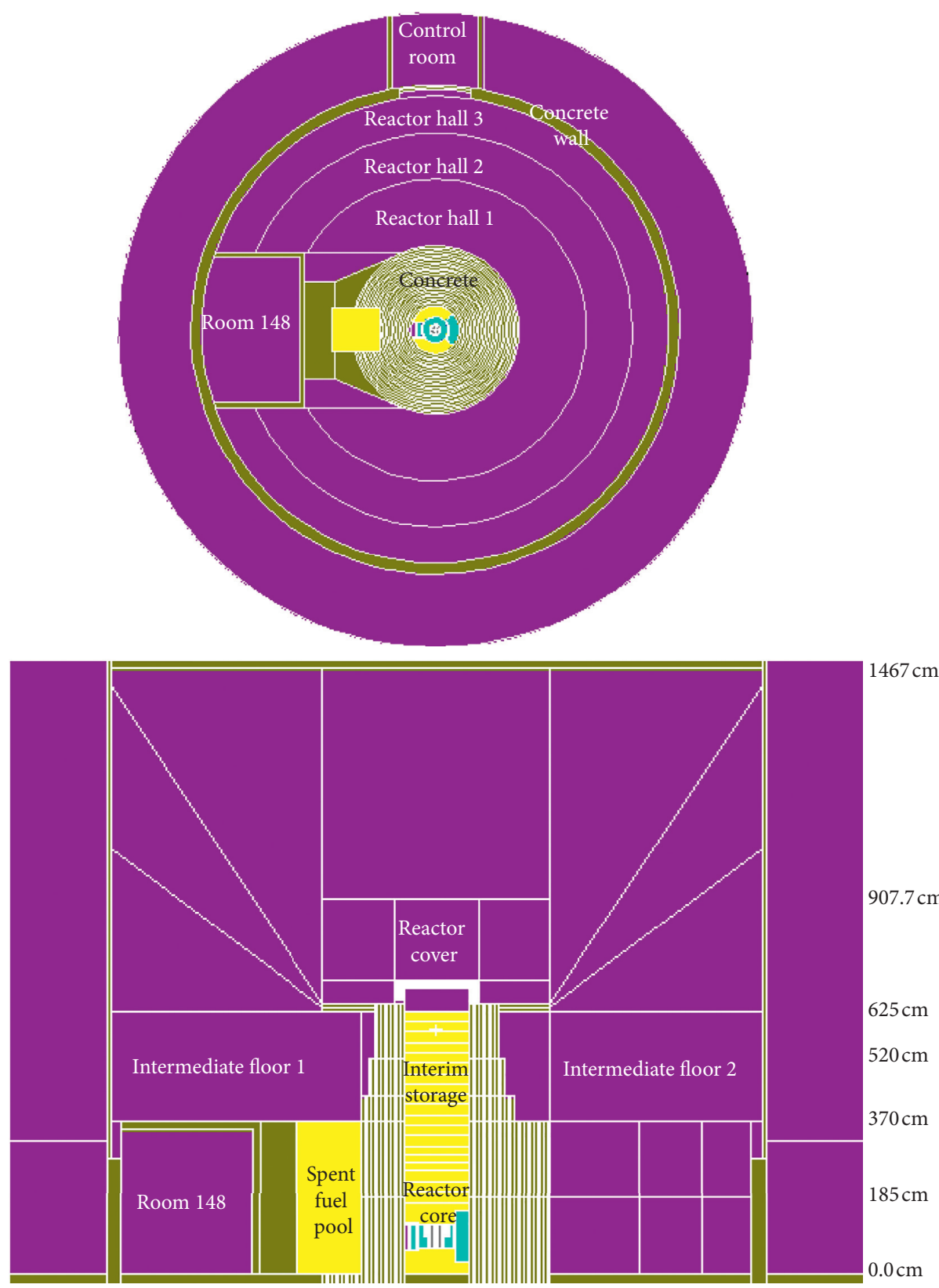

Figure 4: Horizontal (upper) and vertical (lower) cross sections of the radiation safety analysis model in the MCNP5 code.

of water in the reactor tank. Figure 6 displays the vertical layout of the DNRR reactor tank showing the axial levels of water. In the radiation shielding analysis, two photon sources were simulated simultaneously. In the case of complete loss of water, additional calculations were conducted with each of the two sources separately in order to evaluate the contribution of the sources to the total gamma dose rates in comparison between each other. It is because when the water in the reactor tank is completely lost, the LEU core and the interim storage are exposed to the air, and therefore they both contribute significantly to the total dose rates. The gamma dose rates at various places in the reactor hall were evaluated in the most severe cases corresponding to the complete loss of water after 1-day and 7-day cooling.

\section{Results and Analysis}

3.1. Radioactivity and Decay Heat. Figure 7 shows the axial burnup profile of the HEU and LEU fuel bundles with the average burnup of $30 \%$ and $40 \%$ loss of ${ }^{235} \mathrm{U}$, respectively, obtained from the REBUS-MCNP5 calculations. The radioactivity of the HEU and LEU fuel bundles as a function of cooling time obtained from the ORIGEN2.1 calculations is shown in Figure 8. It can be seen that at the cooling time of $5 \mathrm{hrs}$ after the shutdown of the reactor, the radioactivity is decreased by a factor of 5 compared to that at the time of the reactor shutdown. To the end of a day, i.e., 24-hour cooling, the radioactivity is continuously decreased by a factor of 2 . At the cooling time of 20 to 30 days, the radioactivity decreases to about $1480 \times 10^{10} \mathrm{~Bq}$, and this is $850 \times 10^{10} \mathrm{~Bq}$ and 


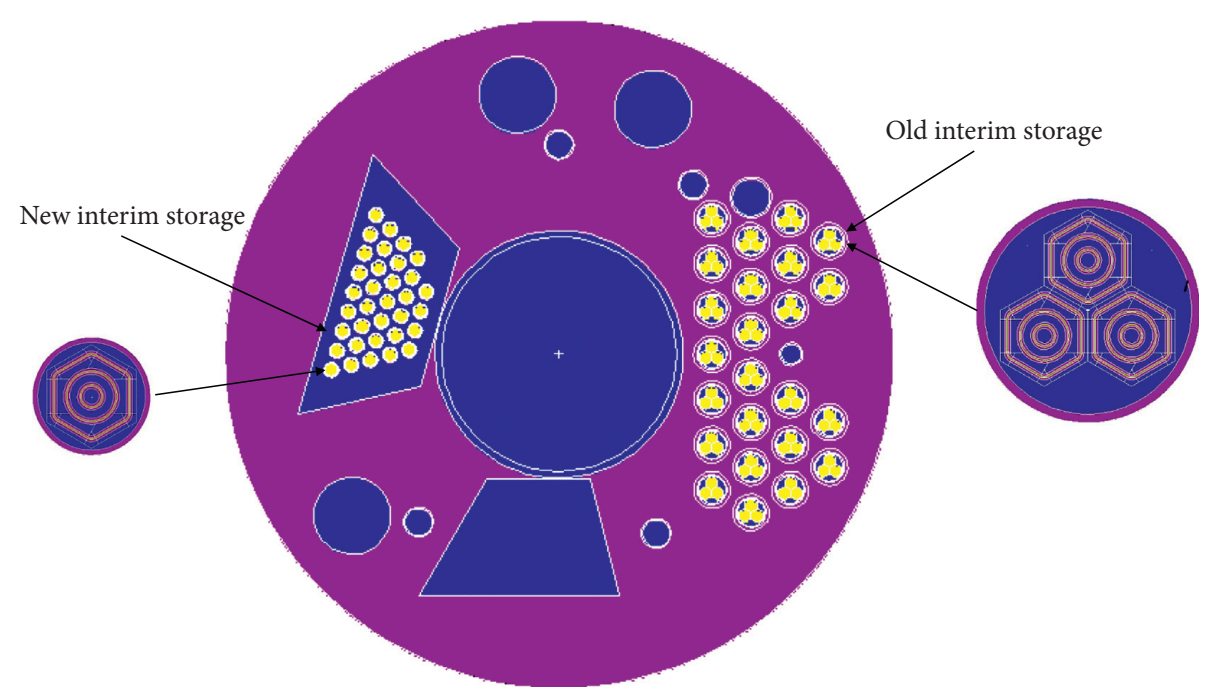

FIGURE 5: Configuration of the interim storage containing 106 spent HEU fuel bundles of the DNRR.

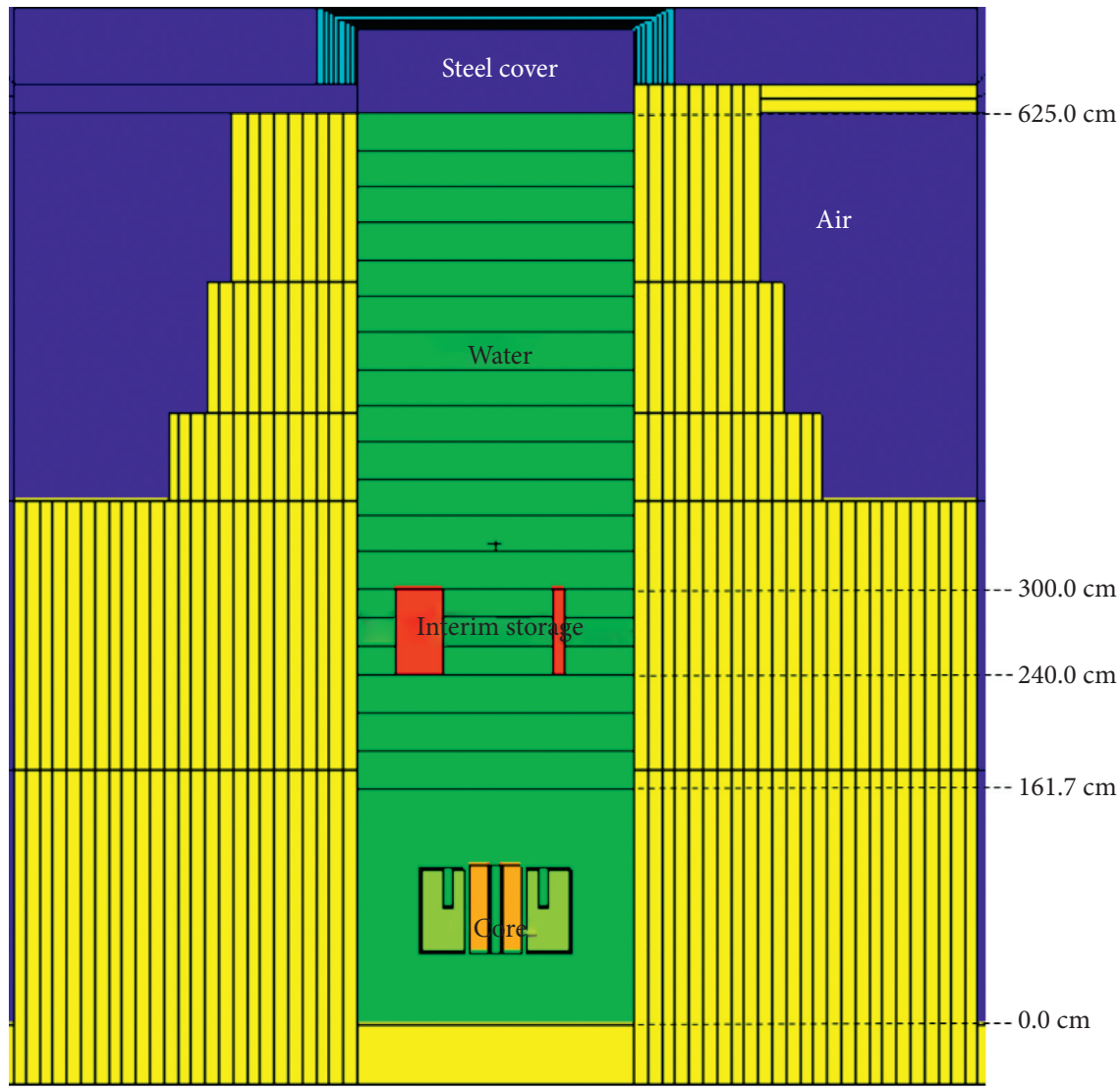

FIGURE 6: Vertical layout of the DNRR reactor tank with axial water levels.

$460 \times 10^{10} \mathrm{~Bq}$ after 100 days and one year, respectively. From this time, the radioactivity decreases slowly. In particular, after 3 and 5 years, the radioactivity is $333 \times 10^{10} \mathrm{~Bq}$ and $278 \times 10^{10} \mathrm{~Bq}$, respectively.

Figure 9 shows the photon flux in the energy range from $0.01 \mathrm{MeV}$ to $9.5 \mathrm{MeV}$ of the spent HEU and LEU fuel bundles at the cooling times of $1 \mathrm{hr}, 1$ day, and 7 days. At the cooling time of $1 \mathrm{hr}$, maximum photon flux of the HEU fuel bundle is higher than that of the LEU fuel bundle. However, at the cooling times of 1 day and 7 days, the maximum photon flux of the LEU fuel bundle is higher. The main reason is due to the contribution of fission products during irradiation.

Decay heat of a spent HEU bundle and an LEU fuel bundle with the burnup of $30 \%$ and $40 \%$ loss of ${ }^{235} \mathrm{U}$, respectively, was evaluated as a function of the cooling time as shown in Table 2. One can see that the decay heat of the fuel 


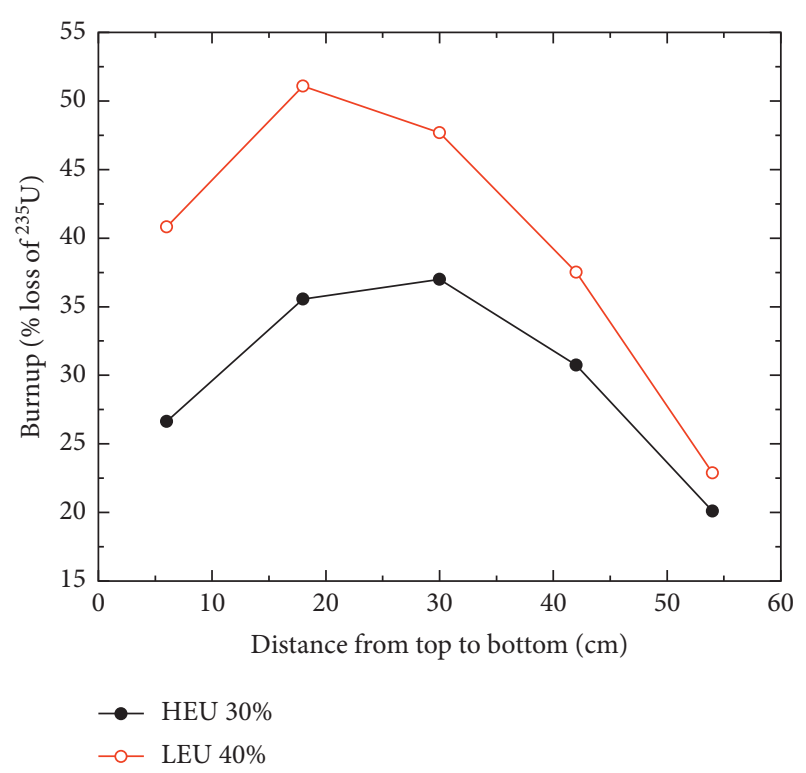

FIGURE 7: Axial burnup profiles of the HEU and LEU fuel bundles with the average burnup of $30 \%$ and $40 \%$ loss of ${ }^{235} \mathrm{U}$, respectively.

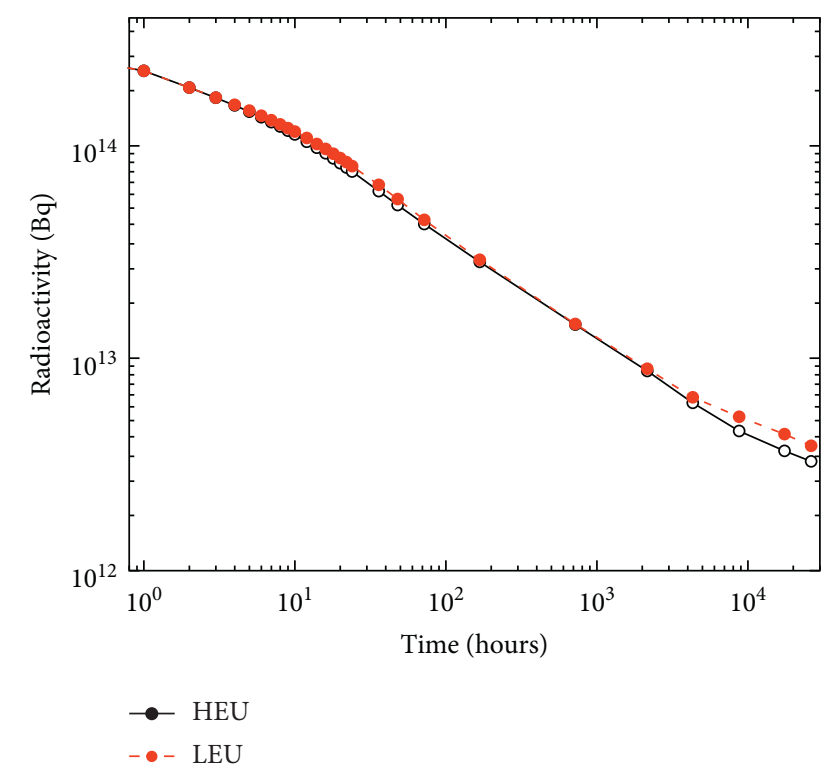

FIGURE 8: Radioactivity of the HEU and LEU fuel bundles with the burnup of $30 \%$ and $40 \%$ loss of ${ }^{235} \mathrm{U}$, respectively, as a function of cooling time.

bundles decreases remarkably by a factor of 25 to 30 after one day cooling. After one week, the decay heat has a small value $(3.2$ to $3.7 \mathrm{~W})$, resulting in a small effect to the fuel cladding. The total decay heat of the 106 spent HEU fuel bundles in the interim storage and the LEU core can be calculated as 29.9 and $25.5 \mathrm{~kW}$, respectively. In principle, the cooling process based on natural convection is established to the spent fuel to be kept in water so that even at the beginning of the shutdown of the reactor, the excessive heating of the fuel bundles would not occur.

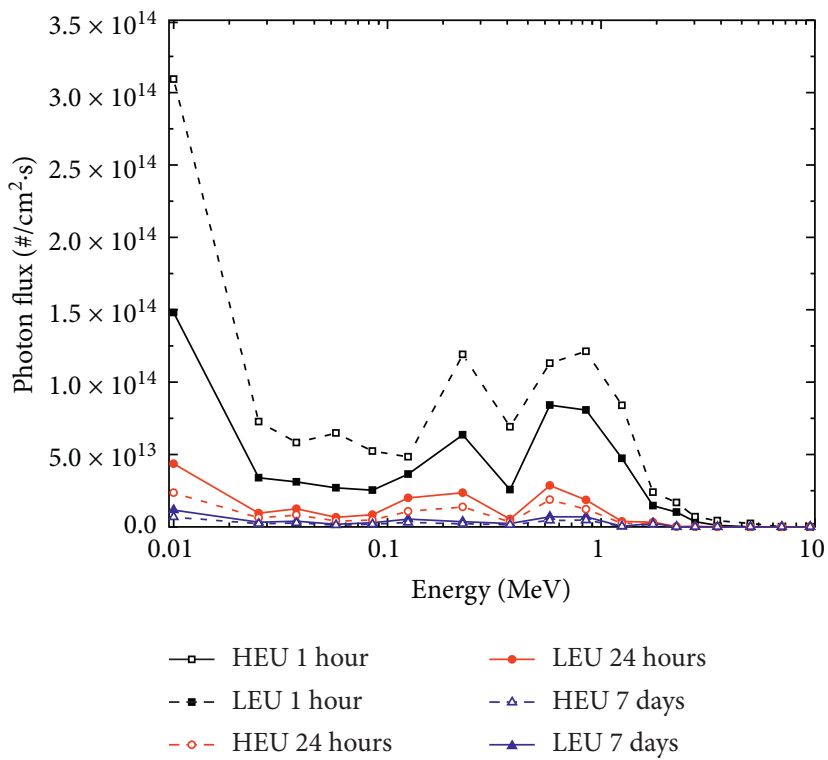

FIgURE 9: Photon flux with 18 energy groups of the spent HEU and LEU fuel bundles at the cooling times of 1 hour, 24 hours, and 7 days.

3.2. Gamma Dose Rates Induced by the Spent Fuel Bundles and the Core. Figure 10 shows the gamma dose rates as a function of water level at one-day cooling. It can be seen that the decrease of the shielding water layer in the reactor tank affects significantly to the gamma dose rate in the reactor cover. In the case of the water level decreases by $100 \mathrm{~cm}$, the dose rate at the reactor cover increases by a factor of 71 . If the water level decreases by $150 \mathrm{~cm}$ (the water level of $475 \mathrm{~cm}$ ), the dose rate at the reactor cover is about $2.4 \mu \mathrm{Sv} / \mathrm{h}$. If the water level decreases to $300 \mathrm{~cm}$, the dose rate at the reactor cover is $3.0 \mathrm{mSv} / \mathrm{h}$, which is considerably high for a person to access into work. The water level of $300 \mathrm{~cm}$ is critical because from this level, the HEU fuel bundles in the interim storage start to be exposed to the air (see Figure 6).

Table 3 shows the contribution of the two sources in the total dose rate in the case of complete loss of water after 1day cooling. In the case of complete loss of water, the gamma dose rate at the reactor cover is about $37 \mathrm{mSv} / \mathrm{h}$ of which the contributions of the 106 spent HEU fuel bundles and the new LEU core are $24 \mathrm{mSv} / \mathrm{h}$ and $13 \mathrm{mSv} / \mathrm{h}$, respectively. According to national safety regulations, the annual dose limits for occupational worker and public are 20.0 and $1.0 \mathrm{mSv} / \mathrm{y}$, respectively. Thus, in the condition with such a high gamma dose rate, a person may receive an annual gamma dose of $20 \mathrm{mSv}$ just within half an hour [13]. In other areas in the reactor hall, persons still can access to mitigate the accident within a limited time. Particularly in the control room, the dose rate is $1.4 \mu \mathrm{Sv} / \mathrm{h}$. This value is equivalent to $2.8 \mathrm{mSv} / \mathrm{y}$, which is smaller than the annual dose limit of $20 \mathrm{mSv} / \mathrm{y}$ for occupational worker according to national safety regulations [13]. Therefore, in the most severe case, the dose rate in the control room is small enough for people to work normally. In practical, the water level alarm system will send a warning if the water loss 
TABle 2: Decay heat of the HEU and LEU fuel bundles with the burnup levels of $30 \%$ and $40 \%$ loss of ${ }^{235} \mathrm{U}$, respectively.

\begin{tabular}{|c|c|c|c|c|c|c|c|}
\hline Cooling time & 0 & $1 \mathrm{hr}$ & 1 day & 1 week & 1 year & 3 years & 10 years \\
\hline \multicolumn{8}{|c|}{ Decay heat (W) of an HEU fuel bundle } \\
\hline Actinides & 1.3847 & 0.5620 & 0.4219 & 0.0839 & 0.0044 & 0.0034 & 0.0036 \\
\hline Fission products & 281.0650 & 48.0725 & 9.2415 & 3.1423 & 0.3947 & 0.2565 & 0.1914 \\
\hline Total & 282.4497 & 48.7781 & 9.6634 & 3.2262 & 0.3991 & 0.2599 & 0.1950 \\
\hline \multicolumn{8}{|c|}{ Decay heat (W) of an LEU fuel bundle } \\
\hline Actinides & 7.0514 & 3.5698 & 2.1820 & 0.5033 & 0.0679 & 0.0466 & 0.0485 \\
\hline Fission products & 270.4489 & 45.9915 & 9.2916 & 3.2192 & 0.4887 & 0.3343 & 0.2509 \\
\hline Total & 277.5003 & 49.5613 & 11.4736 & 3.7225 & 0.5566 & 0.3809 & 0.2995 \\
\hline
\end{tabular}

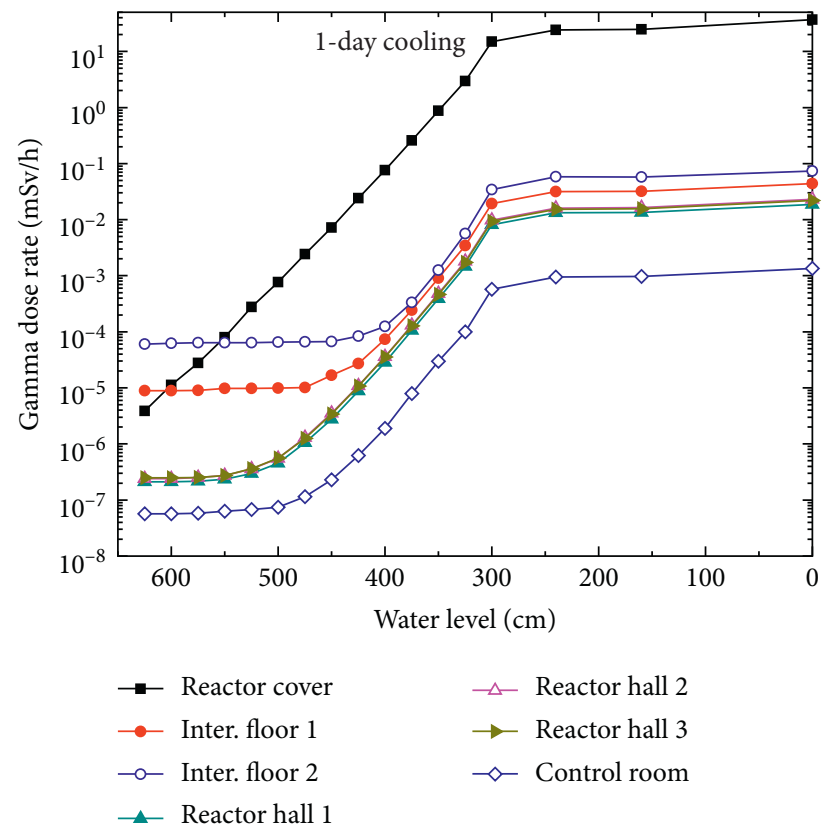

Figure 10: Gamma dose rates $(\mathrm{mSv} / \mathrm{h})$ after 1-day cooling as a function of water level in the reactor tank. The water levels of $625 \mathrm{~cm}$ and $0 \mathrm{~cm}$ correspond to the full water and complete loss of water in the reactor tank, respectively.

TABle 3: Gamma dose rates (mSv/h) after 1-day cooling in the case of complete loss of water.

\begin{tabular}{lccccccc}
\hline Sources of radiation & $\begin{array}{c}\text { Reactor } \\
\text { cover }\end{array}$ & $\begin{array}{c}\text { Intermediate floor } \\
1\end{array}$ & $\begin{array}{c}\text { Intermediate floor } \\
\text { Reactor hall }\end{array}$ & $\begin{array}{c}\text { Reactor hall } \\
2\end{array}$ & $\begin{array}{c}\text { Reactor hall } \\
3\end{array}$ & $\begin{array}{c}\text { Control } \\
\text { room }\end{array}$ \\
\hline $\begin{array}{l}\text { 106 spent HEU fuel } \\
\text { bundles }\end{array}$ & 24.0200 & 0.0314 & 0.0571 & 0.0131 & 0.0159 & 0.0152 \\
$\begin{array}{l}\text { Core with 92 LEU fuel } \\
\text { bundles }\end{array}$ & 12.9700 & 0.0127 & 0.0162 & 0.0056 & 0.0071 & 0.0068 \\
\begin{tabular}{l} 
Total \\
\hline
\end{tabular} & 36.9900 & 0.0441 & 0.0733 & 0.0187 & 0.0230 & 0.00004 \\
\hline
\end{tabular}

exceeds $30 \mathrm{~cm}$ so that the operators have sufficient time to conduct the recovery task.

Figure 11 and Table 4 show the same quantities with Figure 10 and Table 3 but after 7 -day cooling. The gamma dose rates in the reactor hall decrease by a factor greater than 2.0 compared to that after one-day cooling. Comparing the contribution between the two sources, it can be seen that the 106 spent HEU fuel bundles in the interim storage contribute to the total dose rate more than the LEU core by a factor of 2 at most of the locations in the reactor hall.

\section{Conclusions}

Radiation safety analysis has been performed for the new interim storage of the DNRR for keeping the spent fuel during the core conversion from HEU fuel to LEU fuel. The new interim storage was designed to extend the existing capacity for containing 106 spent HEU fuel bundles in the reactor tank. Calculations of the gamma dose rates at various positions in the reactor halls and control room induced by both the spent fuel bundles in the storage and the LEU core have been conducted. A computational procedure has been developed to 


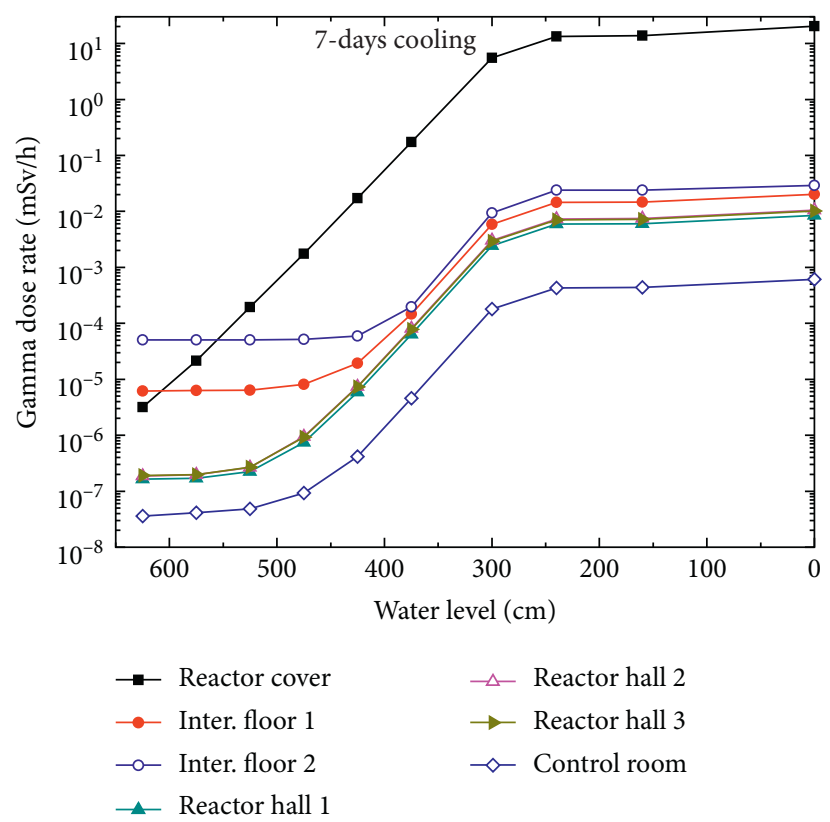

Figure 11: Gamma dose rates ( $\mathrm{mSv} / \mathrm{h}$ ) after 7-day cooling as a function of water level. The water levels of $625 \mathrm{~cm}$ and $0 \mathrm{~cm}$ correspond to the full water and complete loss of water in the reactor tank, respectively.

TABle 4: Gamma dose rates (mSv/h) after 7-day cooling in the case of complete loss of water.

\begin{tabular}{|c|c|c|c|c|c|c|c|}
\hline Sources of radiation & $\begin{array}{c}\text { Reactor } \\
\text { cover }\end{array}$ & $\begin{array}{c}\text { Intermediate floor } \\
1\end{array}$ & $\begin{array}{c}\text { Intermediate floor } \\
2\end{array}$ & $\begin{array}{c}\text { Reactor hall } \\
1\end{array}$ & $\begin{array}{l}\text { Reactor hall } \\
2\end{array}$ & $\begin{array}{c}\text { Reactor hall } \\
3\end{array}$ & $\begin{array}{c}\text { Control } \\
\text { room }\end{array}$ \\
\hline $\begin{array}{l}106 \text { spent HEU fuel } \\
\text { bundles }\end{array}$ & 1.3250 & 0.0143 & 0.0231 & 0.0059 & 0.0072 & 0.0070 & 0.0004 \\
\hline $\begin{array}{l}\text { Core with } 92 \text { LEU fuel } \\
\text { bundles }\end{array}$ & 0.7075 & 0.0058 & 0.0059 & 0.0026 & 0.0033 & 0.0032 & 0.0002 \\
\hline Total & 2.0325 & 0.0201 & 0.0290 & 0.0085 & 0.0106 & 0.0102 & 0.0006 \\
\hline
\end{tabular}

couple WIMS-ANL for generating burnup-dependent cross sections of the fuel bundles, ORIGEN2.1 for calculating 18group photon flux, REBUS-MCNP5 for calculating axial burnup distributions of the fuel bundles, and MCNP5 for calculating gamma dose rates. Radiation analysis has been performed with the assumption of various scenarios of loss of water level in the reactor tank. In the case of the loss of water level less than $100 \mathrm{~cm}$, the gamma dose induced by the 106 spent HEU fuel bundles does not affect people working in the reactor hall. In the most severe case that the water level in the reactor tank is completely lost and the cooling time is one day, the operators still can access the reactor hall for repairing in a limited time. In the control room, the gamma dose rate is about $1.4 \mu \mathrm{Sv} / \mathrm{h}$ or equivalent to $2.8 \mathrm{mSv} / \mathrm{y}$. This value is less than the annual dose limit of $20 \mathrm{mSv} / \mathrm{y}$ for occupational worker, and therefore, allowing normal operation in the control room. The results indicate that the retention of 106 spent HEU fuel bundles in the newly designed interim storage is fully met the requirements of the radiation safety at the normal operation condition of the new LEU core.

\section{Data Availability}

The data used to support the findings of this study are available from the corresponding author upon request.

\section{Conflicts of Interest}

The authors declare that there are no conflicts of interest regarding the publication of this article.

\section{Acknowledgments}

This research was performed as part of the employment of the authors at Dalat Nuclear Research Institute. H. N. Tran was supported, in part, by the Vietnam National Foundation for Science and Technology Development (NAFOSTED) under grant 103.04-2020.06.

\section{References}

[1] N. D. Nguyen, Safety Analysis Report for the Dalat Nuclear Research Reactor, Nuclear Research Institute, Vietnam Atomic Energy Institute, Dalat, Vietnam, 2009.

[2] N. D. Nguyen, B. V. Luong, V. V. Le et al., "Results of operation and utilization of the Dalat nuclear research reactor," Nuclear Science and Technology, vol. 4, no. 1, pp. 1-9, 2014.

[3] Q. B. Do, H.-N. Tran, Q. H. Ngo, and G. T. T. Phan, "Determination of fuel burnup distribution of a research reactor based on measurements at subcritical conditions," Nuclear Science and Techniques, vol. 29, no. 12, p. 174, 2018. 
[4] A. G. Croff, A User Manual for the ORIGEN2 Computer Code, Oak Ridge National Laboratory, Oak Ridge, TN, USA, 1980.

[5] S. Ludwig, ORIGEN2, Version 2.1 (August 1, 1991) Release Notes, Oak Ridge National Laboratory, Oak Ridge, TN, USA, 1999.

[6] J. R. Deen, W. L. Woodruff, C. I. Costescu, and L. S. Leopando, WIMS-ANL User Manual Rev. 5. ANL/RERTR/TM-99-07, Argonne National Laboratory, Chicago, IL, USA, 2003.

[7] X-5 Monte Carlo Team, MCNP-A General Monte Carlo $N$-Particle Transport Code, Los Alamos National Laboratory, Santa Fe, NM, USA, 2003.

[8] G. Phan, H.-N. Tran, K.-C. Nguyen et al., "Comparative analysis of the Dalat nuclear research reactor with HEU fuel using SRAC and MCNP5," Science and Technology of Nuclear Installations, vol. 2017, Article ID 2615409, 10 pages, 2017.

[9] Q. B. Do, G. T. T. Phan, K.-C. Nguyen, Q. H. Ngo, and H.-N. Tran, "Criticality and rod worth analysis of the DNRR research reactor using the SRAC and MCNP5 codes," Nuclear Engineering and Design, vol. 343, pp. 197-209, 2019.

[10] CSEWG-Collaboration, Evaluated Nuclear Data File ENDF/ $B$-VI.8, National Nuclear Data Center, Long Island, NY, USA, 2001, https://www.nndc.bnl.gov/endf.

[11] J. G. Stevens, The REBUS-MCNP Linkage, Argonne National Laboratory, ANL/RERTR/TM-08-04, Chicago, IL, USA, 2008.

[12] American National Standards Institute Inc, American $\mathrm{Na}$ tional Standard Neutron and Gamma-Ray Flux-To-Dose-Rate Factors, ANSI, New York, NY, USA, 1977.

[13] IAEA Safety Standards, International Basic Safety Standards for Protection against Ionizing Radiation and for the Safety of Radiation Sources. Series No. 115, IAEA, Vienna, Austria, 1996. 